Article

\title{
A Modified Gash Model for Estimating Rainfall Interception Loss of Forest Using Remote Sensing Observations at Regional Scale
}

\author{
Yaokui Cui ${ }^{1,2}$ and Li Jia ${ }^{1, *}$
}

1 State Key Laboratory of Remote Sensing Science, Institute of Remote Sensing and Digital Earth, Chinese Academy of Sciences, Beijing 100101, China; E-Mail: cuiyk@radi.ac.cn

2

University of Chinese Academy of Sciences, Beijing 100049, China

* Author to whom correspondence should be addressed; E-Mail: jiali@radi.ac.cn;

Tel.: +86-10-6480-7982; Fax: +86-10-6480-7982.

Received: 11 February 2014; in revised form: 7 April 2014 / Accepted: 10 April 2014 /

Published: 22 April 2014

\begin{abstract}
Rainfall interception loss of forest is an important component of water balance in a forested ecosystem. The Gash analytical model has been widely used to estimate the forest interception loss at field scale. In this study, we proposed a simple model to estimate rainfall interception loss of heterogeneous forest at regional scale with several reasonable assumptions using remote sensing observations. The model is a modified Gash analytical model using easily measured parameters of forest structure from satellite data and extends the original Gash model from point-scale to the regional scale. Preliminary results, using remote sensing data from Moderate Resolution Imaging Spectroradiometer (MODIS) products, field measured rainfall data, and meteorological data of the Automatic Weather Station (AWS) over a picea crassifolia forest in the upper reaches of the Heihe River Basin in northwestern China, showed reasonable accuracy in estimating rainfall interception loss at both the Dayekou experimental site $\left(R^{2}=0.91, R M S E=0.34 \mathrm{~mm} \cdot \mathrm{d}^{-1}\right)$ and the Pailugou experimental site $\left(R^{2}=0.82, R M S E=0.6 \mathrm{~mm} \cdot \mathrm{d}^{-1}\right)$, compared with ground measurements based on per unit area of forest. The interception loss map of the study area was shown to be strongly heterogeneous. The modified model has robust physics and is insensitive to the input parameters, according to the sensitivity analysis using numerical simulations. The modified model appears to be stable and easy to be applied for operational estimation of interception loss over large areas.
\end{abstract}


Keywords: interception loss; remote sensing; forest; regional scale; Gash model

\section{Introduction}

Rainfall interception loss is the proportion of gross rainfall that is intercepted, stored and subsequently evaporated from all parts of vegetation during or following rainfall. Many studies on rainfall interception loss observations and modeling in forest have been carried out and it has been reported that rainfall interception loss totals were between $10 \%$ and $40 \%$ of annual gross rainfall [1-3]. Therefore, studying the interception loss of forest is very important for improving the modeling of regional and global water balances and understanding the terrestrial water cycle processes [4].

Until now, many researchers have developed a series of rainfall interception models including: the empirical statistical model [5] and the physically-based model [6-11]. The latter has been paid more attention due to its robustness in physics and less need for calibration of empirical coefficients. Almost all of the physically-based models have been derived from the Rutter (1972) model [7] and the Gash (1979) and (1995) models [6,8]. Applications have covered different types of vegetation including rainforest, conifers, mixed conifer, shrubs, crops, etc. Most of these applications, however, were at field scale [12].

Satellite remote sensing observations can provide land surface information with high spatial and temporal resolution. Unfortunately, estimate of interception loss at regional scale using remote sensing information is not straight forward. Empirically based models have been applied to remote sensing observations for regional estimate of interception evaporation. Bastiaanssen et al. [13] used the classical von Hoyningen algorithm [14] to calculate the interception evaporation. Such a method has an implication that maximum interception loss will stay below the vegetation storage capacity for single rainfall and will therefore underestimate interception loss for large rainfalls. Mu et al. [15] considered evaporation from a wet canopy surface according to the fractional canopy water cover defined by the relative humidity by setting a threshold of relative humidity in priori. On the contrary, physically-based sophisticated models with solid physical meaning are usually too complex so that parameters needed in such models often cannot be obtained from remote sensing observations.

The Gash (1979 and 1995) models have been widely used and verified in weekly and monthly temporal scales at different sites [8,16-19]. For most researchers only paid attention to the long-term interception loss of forest, the applicability of the Gash model in estimating daily interception loss has not been effectively verified. The Gash (1979) model considered rainfall to occur as a series of discrete events, during which three phases can be distinguished: a wetting phase, a saturation phase, and a drying phase after rainfall has ceased. Based on this, the interception loss of canopy is calculated by the canopy storage capacity, canopy coverage, and the ratio of mean evaporation rate from wet canopy over mean rainfall rate. The interception loss of trunk is calculated by the trunk storage capacity and the proportion of the rainfall diverted to stemflow. The main improvement of the Gash (1995) model is that the wet canopy evaporation rate per unit ground area is linearly dependent on the canopy cover fraction. Since then, there have also been many researchers who have proposed significant improvements at field scale over the Gash (1995) model, e.g., van Dijk [10] 
adapted the Gash model for vegetation whose characteristics change markedly during the growing season, by relating the canopy capacity and evaporation rate from a saturated canopy to leaf area index (LAI), but was not given much consideration, as reviewed in [12].

The results of site-based studies have limited representability for regional scale since forest canopy is often shown to be inhomogeneous with large spatial and temporal variability in its stand distribution, LAI and canopy fractional coverage. There are still many difficulties when applying the Gash model at regional scale. One of the most important reasons is that the model calculates the interception loss of canopy and trunk separately, so that more parameters need to be known as a priori but which are usually difficult to extrapolate from field scale to regional scale. In spite of some researchers suggesting that the canopy storage capacity is linearly linked with LAI $[10,20]$, it is still difficult to obtain parameters about trunks at regional scale. In fact, LAI normally refers to the total one-sided area of all green canopy elements per unit ground area [21], which does not include other parts of canopy, e.g., dead leaves. One case among very rare applications at regional scale is made by Miralles et al. [22]. However, they used a single set of parameters derived from statistics from literature for calculation of interception loss over the entire region of their study.

Nowadays, remote sensing can provide many variables or inputs needed by the Gash model, for instance LAI, Fractional Vegetation Cover (FVC). Very few attempts have been made in applying these satellite observed parameters to Gash models, since there are still a few critical parameters which cannot be directly derived from remote sensing observations, e.g., canopy storage capacity, trunk storage capacity and the proportion of the rainfall diverted to stemflow.

The objective of this study is to develop a simple and practical forest interception loss model to satisfy the requirements of interception loss estimate of heterogeneous forest at regional scale. This model is a modified forest interception loss model based on the Gash (1979 and 1995) models, referred to as the RS-Gash model (remote sensing based Gash model), by introducing remote sensing observations of Vegetation Area Index (VAI) and FVC. The RS-Gash model was verified using measurements collected at two forest hydrology experimental sites. The sensitivity analysis of the model was done by varying the inputs one-by-one, to test the robustness of the model. Finally, some conclusions about the RS-Gash model are summarized.

\section{Theory of the Gash Model}

The Gash model [6] was widely used initially to estimate interception loss of forest taking into account rainfall rate, forest canopy, trunk and meteorological factors. Improvements were made in a later work applicable to sparse forest canopy [8].

According to the amount of gross rainfall necessary to saturate the canopy $\left(P_{G}^{\prime}\right)$ and the amount of gross rainfall necessary to saturate the trunk $\left(S_{t} / p_{t}\right)$, where $S_{t}$ is the trunk storage capacity and $p_{t}$ is the proportion of the rainfall diverted to stemflow, rainfall can be divided into three categories: (i) the gross rainfall $\left(P_{G}\right)$ is not larger than $P_{G}^{\prime}$ so that forest canopy is not saturated, and interception loss is equal to $c \cdot P_{G}$, where $c$ is canopy coverage; (ii) the gross rainfall $P_{G}$ is larger than $P_{G}^{\prime}$ but not larger than $S_{t} / p_{t}$ so that forest canopy is saturated but the trunk is not, and the interception loss is equal to $c \cdot P_{G}^{\prime}+c \cdot \overline{E_{C}} / \bar{R} \cdot\left(P_{G}-P_{G}^{\prime}\right)+p_{t} \cdot P_{G}$, where $\overline{E_{C}}\left(\mathrm{~mm} \cdot \mathrm{h}^{-1}\right)$ is the mean evaporation rate per unit canopy cover when the forest canopy is saturated; $\bar{R}\left(\mathrm{~mm} \cdot \mathrm{h}^{-1}\right)$ is the mean rainfall rate for saturated canopy condition, 
which includes the canopy storage, evaporation from the wetting canopy and the part of rainfall diverted into trunks; (iii) the gross rainfall $P_{G}$ is larger than $S_{t} / p_{t}$ so that both forest canopy and trunk are saturated, and the interception loss is equal to $c \cdot P_{G}^{\prime}+c \cdot \overline{E_{C}} / \bar{R} \cdot\left(P_{G}-P_{G}^{\prime}\right)+S_{t}$, which includes the canopy storage, trunk storage, and evaporation during rainfall, which implies that the evaporation from wet trunk was neglected. Then, the interception loss of canopy and trunk were calculated separately. So in the Gash analytical model, interception loss of forest consists of interception loss of canopy and interception loss of trunk.

It is generally assumed that there is one rainfall event per day so that the Gash model can be used to calculate the interception loss on a daily scale. For a single rainfall, the amount of gross rainfall necessary to saturate the canopy $P_{G}^{\prime}$ is given by:

$$
P_{G}^{\prime}=-\frac{\bar{R}}{\bar{E}_{C}} \cdot \frac{S}{c} \ln \left(1-\frac{\overline{E_{C}}}{\bar{R}}\right)
$$

where, $S$ is the storage capacity of canopy per unit area of ground and $c$ is the canopy cover. In the original Gash (1995) model, the mean evaporation rate $\overline{E_{C}}$ and mean rainfall rate $\bar{R}$ are obtained in the whole experimental period to replace each four-week period as in the Gash (1979) model and it is assumed that the ratio $\overline{E_{C}}$ over $\bar{R}$ is equal for all storms to still get satisfactory results.

The interception loss of canopy $\left(I_{c}\right)$ can be calculated by:

$$
\begin{cases}I_{c}=c \cdot P_{G} & \text { for }\left(P_{G}<P_{G}^{\prime}\right) \\ I_{c}=c \cdot P_{G}^{\prime}+\left(c \cdot \overline{E_{C}} / \bar{R}\right)\left(P_{G}-P_{G}^{\prime}\right) & \text { for }\left(P_{G}>P_{G}^{\prime}\right)\end{cases}
$$

The interception loss of trunk $\left(I_{t}\right)$ can be calculated by:

$$
\begin{cases}I_{t}=S_{t} & \text { for }\left(P_{G} \geq S_{t} / p_{t}\right) \\ I_{t}=p_{t} \cdot P_{G} & \text { for }\left(P_{G}<S_{t} / p_{t}\right)\end{cases}
$$

Since the Gash model calculates the interception loss of canopy and trunk as two parts separately, it needs a large number of parameters, such as $\overline{E_{C}}, \bar{R}, c, S_{c}, S_{t}$ and $p_{t}$. When applying the Gash model at regional scale, many parameters such as $S_{t}$ and $p_{t}$ are difficult to obtain.

\section{RS-Gash Model for Regional Scale Estimation}

\subsection{The RS-Gash Model Assumptions}

As stated above, there are no methods to directly calculate $S_{t}$ and $p_{t}$ using other easily measured forest structure parameters, while existing methods to calculate $S_{c}$ using LAI can only partly represent $S_{c}$ in the application of the original Gash model. Treating $S_{t}$ and $p_{t}$ as constant at regional scale is a possible way with the uniformity forest, however in a heterogeneous forest it is not, and the latter case is more common in our world. Besides, when calculating the interception loss, the heterogeneity within a pixel is still not included in the model. Here, the RS-Gash model was proposed to simplify the Gash (1995) model, so that the interception loss of heterogeneous forest can be obtained using remote sensing observations at regional scale. The major improvement of the RS-Gash model is that the interception loss is calculated based on the whole vegetation (forest), not on canopy and trunk separately, and 
meanwhile the heterogeneity within a pixel is also considered. The RS-Gash model is based on the following hypotheses:

1. The leaves, branches and trunks of forest are treated as one unit so there is no distinction between canopy and trunk as in the original Gash (1995) model. A term of vegetation storage capacity per unit area of ground $\left(S_{v e g}\right)$ is introduced to replace the $S$ and $S_{t}$ in the original Gash (1995) model. "Vegetation" here indicates all elements of forest including leaves (green and dry), branches, and trunk. The vegetation storage capacity $S_{\text {veg }}$ is linearly related to Vegetation Area Index (VAI), the latter includes green leaves, dry leaves, branches, and trunk areas;

2. Accordingly, a term of mean evaporation rate per unit vegetation coverage area from saturated vegetation surfaces $\left(\overline{E_{V}}\right)$ is introduced assuming the saturated canopy and saturated trunk have the same evaporation rate. The hypothesis is inherited that $\overline{E_{V}} / \bar{R}$ is equal for all storms as used in the original Gash (1995) model;

3. In the RS-Gash model, for one pixel of satellite image, the VAI is divided into several sub-pixels by Poisson distribution. Each sub-pixel is treated as having homogeneous distribution of VAI when calculating the interception loss of it. The interception loss of the entire pixel is the integration of all sub-pixels by the Poisson distribution probability. The interaction effect among different sub-pixels in one pixel is neglected.

Based on these assumptions, the RS-Gash model can be described as follows. For a single rainfall, according to assumption (3), the interception loss of one pixel is described as:

$$
I=\sum_{i=1}^{n} P b_{i} \cdot I_{i}
$$

where $I_{i}$ is the interception loss of the $i$-th sub-pixel of the pixel, and $P b_{i}$ is the corresponding probability which will be given in Section 3.4.

For the $i-t h$ sub-pixel, the amount of gross rainfall necessary to saturate the vegetation $\left(P_{G, i}^{\prime}\right)$ now can be expressed as:

$$
P_{G, i}^{\prime}=-\frac{\bar{R}}{\overline{E_{V}}} \cdot \frac{S_{v e g}}{F V C} \cdot \ln \left(1-\frac{\overline{E_{V}}}{\bar{R}}\right)
$$

All the variables and parameters in Equation (5) have been defined before.

For low rainfall $\left(P_{G}<P_{G, i}^{\prime}\right)$, the interception loss of one sub-pixel $\left(I_{i}\right)$ is given by:

$$
I_{i}=F V C \cdot P_{G}
$$

For high rainfall $\left(P_{G}>P_{G, i}^{\prime}\right), I_{i}$ is given by:

$$
I_{i}=F V C \cdot P_{G, i}^{\prime}+\left(F V C \cdot \overline{E_{V}} / \bar{R}\right)\left(P_{G}-P_{G, i}^{\prime}\right)
$$

The ratio of $\overline{E_{V}}$ over $\bar{R}$ should be obtained during a single rainfall. However, considering the measurement error especially for a short duration of rainfall, this ratio may not be stable or even not possible to obtain. So, the ratio for a long-term (the whole experimental period in this paper) is a feasible replacement, based on the assumption (2) and the sensitivity analysis of the model in Section 5.4. In the RS-Gash model, all of the parameters, that is mean evaporation rate $\overline{E_{V}}$, mean 
rainfall rate $\bar{R}$, vegetation storage capacity $S_{\text {veg }}$, VAI and FVC, could be obtained from remote sensing observations, using the existing methods or the methods described below.

\subsection{Vegetation Storage Capacity}

Gash-like models divide the interception loss of forest into two parts: interception loss of canopy and trunk $[4,5,8,9,23]$. Some researchers thought that the canopy storage capacity was more important because the trunk's surface area is relatively small and the rain can reach the trunk only when the rainfall is large enough [8]. Gash considered that the canopy storage capacity is linear with canopy coverage (c) [8]. Many researchers have suggested that the canopy storage capacity has a linear relationship with LAI, e.g., Bastiaanssen et al. [13] used one empirical coefficient to represent the canopy storage capacity per unit LAI, Pitman [23] obtained the relationship between canopy storage capacity and LAI by regression using ground measurements, Liu [9] and van Dijk and Bruijnzeel [10] considered linear relationship reasonably exiting between $S$ and LAI. However, this still cannot explain the interception loss of forest in a leafless period, as Llorens and Gallart [24] noted in that the water retained in branches and stems plays a key role in rainfall interception. It is reasonable that all parts of the forest have the ability to hold rainfall and not only the leaves. Assuming a linear relationship existing between $S_{v e g}$ and VAI, the vegetation storage capacity per unit area of ground $S_{v e g}$ that includes canopy storage capacity and trunk storage capacity can be expressed as:

$$
S_{\text {veg }}=S_{V} \cdot V A I
$$

where $S_{V}$ is specific vegetation storage, defined as the depth of water that can be retained by vegetation per unit vegetation area, which can be determined experimentally for a particular species using laboratory methods described for instance by Aston [25] and Liu [9] or the regression method on throughfall data [26]. This implies that the leaf and other parts of forest have the same $S_{V}$.

At regional scale, the VAI can be calculated from the Moderate Resolution Imaging Spectroradiometer (MODIS) products of LAI by the methods proposed by Zeng et al. [21]:

$$
V A I=L A I_{g}+L_{s}
$$

where $L A I_{g}$ is the green leaf-area index, which can be provided by the MODIS LAI product; $L_{s}$ is the area index of branches, trunk and dead leaves and can be obtained by:

$$
L_{s}^{n}=m \operatorname{ax}\left\{\left[\alpha \cdot L_{s}^{n-1}+\max \left(L A I_{g}^{n-1}-L A I_{g}^{n}, 0\right)\right], L_{s, \min }\right\}
$$

where $n$ denotes the nth component in the $L_{s}$ time series; $L_{s, \min }$ is the prescribed minimum value of $L_{s}$; $(1-\alpha)$ is the removal rate of dead leaves between two products [21].

\subsection{Mean Evaporation Rate from Saturated Vegetation}

Evaporation of intercepted rainfall from forest consists of two parts: one is the evaporation from the tree canopy, and the other is from the trunk. Evaporation rate is often calculated by the Penman-Monteith equation by setting the surface resistance to zero [27]:

$$
\lambda E=\left(\Delta R_{n}+\rho c_{p} D / r_{a}\right)(\Delta+\gamma)^{-1}
$$




$$
r_{a}=\ln \left((z-d) / z_{0}\right)^{2} /\left(\kappa^{2} u\right)
$$

where $E\left(\mathrm{~kg} \cdot \mathrm{m}^{-2} \cdot \mathrm{s}^{-1}\right)$ is the evaporation rate; $\lambda\left(\mathrm{J} \cdot \mathrm{kg}^{-1}\right)$ is the latent heat of vaporization; $R_{n}\left(\mathrm{~W} \cdot \mathrm{m}^{-2}\right)$ is the net radiation; $c_{p}\left(\mathrm{~J} \cdot \mathrm{kg}^{-1} \cdot \mathrm{K}^{-1}\right)$ is the specific heat capacity of air at constant pressure; $D(P a)$ is the vapor pressure deficit; $\gamma\left(\mathrm{Pa} \cdot \mathrm{K}^{-1}\right)$ is the psychrometric constant; $\Delta\left(\mathrm{Pa} \cdot \mathrm{K}^{-1}\right)$ is the slope of the saturation vapor pressure curve at air temperature; $\rho\left(\mathrm{kg} \cdot \mathrm{m}^{-3}\right)$ is the density of air; $r_{a}\left(\mathrm{~s} \cdot \mathrm{m}^{-1}\right)$ is the aerodynamic resistance; $z(m)$ is the height of wind speed $u\left(s \cdot m^{-1}\right)$ measurements; the roughness length parameters are $d=0.75 h$ and $z_{0}=0.1 h, h(m)$ is the vegetation height; and $\kappa(0.41)$ is the von-Karman constant.

It is reasonable to treat the evaporation rate of the saturated canopy and the saturated trunk equally assuming all parts of forest have similar net radiation (per unit area), vapor pressure deficit and other atmospheric forcing factors. As Gash [8] pointed out, the mean evaporation rate per unit ground is linearly correlated with the canopy cover $(c)$ for spare forest. As mentioned earlier, a new term - the mean evaporation rate from saturated vegetation, $\overline{E_{V}}$ — is introduced to represent the total evaporation from forest canopy and trunk per unit vegetation cover. Consequently, the FVC is considered more adequate than canopy cover $(c)$ to calculate the mean evaporation per unit ground area $(\bar{E})$. Although $\mathrm{FVC}$ and $c$ show almost no difference for the leafed period, a large difference for the leafless period may exist between the two. Hence, the mean evaporation rate from saturated canopy per unit ground area $\bar{E}$ is expressed by:

$$
\bar{E}=\overline{E_{V}} \cdot F V C
$$

Note that the ratio $\overline{E_{V}} / \bar{R}$ is assumed to be constant when FVC is varying.

At regional scale, the FVC can be calculated from the satellite observed parameter Normalized Difference Vegetation Index (NDVI) by the methods used in Bastiaanssen et al. [13]:

$$
F V C=1-\left(\frac{N D V I_{f v}-N D V I}{N D V I_{f v}-N D V I_{b s}}\right)^{0.7}
$$

where $N D V I_{f v}$ and $N D V I_{b s}$ are the threshold values of full vegetation cover and bare soil, respectively.

\subsection{Heterogeneous Vegetation at Sub-Pixel Scale}

The heterogeneity of vegetation at pixel scale can be described by VAI and FVC. Most of the interception loss models did not take into account the sub-pixel heterogeneity, for they are based on uniformity forest hypothesis that assumes that the forest reaches saturation at almost the same time. Unfortunately, forest often is characterized by very large spatial heterogeneity. Larger VAI implies taking longer time to reach saturation. There are mainly three forms describing the spatial distribution of VAI according to the distribution of canopy elements: regular distribution, random distribution and irregular distribution [28]. The random distribution is the normal form and widely used. The Poisson distribution function is applied to take account of the random distribution to describe effects of heterogeneity of forest density of coverage on interception loss.

The Poisson distribution scheme of a pixel is presented in Figure 1.

If a pixel with an average value of VAI is divided into $\mathrm{n}$ sub-pixels according to the Poisson distribution, the pixel value of VAI can be described as the composite of the VAI values of the Poisson-distribution-divided sub-pixels by the equation: 


$$
V A I=\sum_{i=1}^{n} P b_{i} \cdot V A I_{i}
$$

where $P b_{i}$ is the proportion of sub-pixels where $V A I=V A I_{i}$ have the same FVC as the pixel. The interior of sub-pixels in a pixel can be treated as homogeneous when calculating the interception loss. Consequently, the sub-pixels with different VAI values will have a different time and gross rainfall requirement to reach saturation.

Figure 1. Schematic representation of spatial heterogeneity of Vegetation Area Index (VAI) in a pixel.

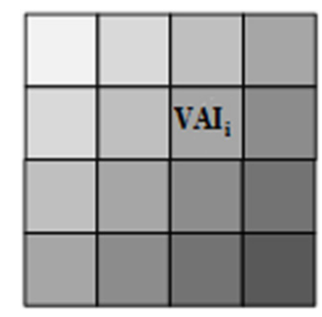

\section{Study Area and Data}

\subsection{Study Area}

The study area is a part of the water conservation forest in the Qilian Mountain, in the upper reaches of the Heihe River Basin in northwestern China, which lies between latitude $38^{\circ}-39^{\circ} \mathrm{N}$ and longitude $99^{\circ}-101.5^{\circ} \mathrm{E}$, with elevation ranging between $1450 \mathrm{~m}$ and $4900 \mathrm{~m}$ (Figure 2). The field experiment is a part of Watershed Allied Telemetry Experimental Research (WATER) [29]. This part of the basin exhibits complex hydrological processes due to variability in topography, rainfall and land cover. The annual precipitation varies approximately between $400 \mathrm{~mm}$ and $600 \mathrm{~mm}$, and the mean annual air temperature is about $0.7^{\circ} \mathrm{C}$. Picea crassifolia is the major species covering about $76.8 \%$ of the forest in this region [29].

Figure 2. Map of the Heihe River Basin (A); study area (B); and Dayekou and Pailugou experimental sites (the two small false color images) (C). The map is from MODIS NDVI on 27 June 2008. The false color image is from Hyperion on 15 June 2008 with resolution of $30 \mathrm{~m}$, within a $0.01^{\circ} \times 0.01^{\circ}$ grid.

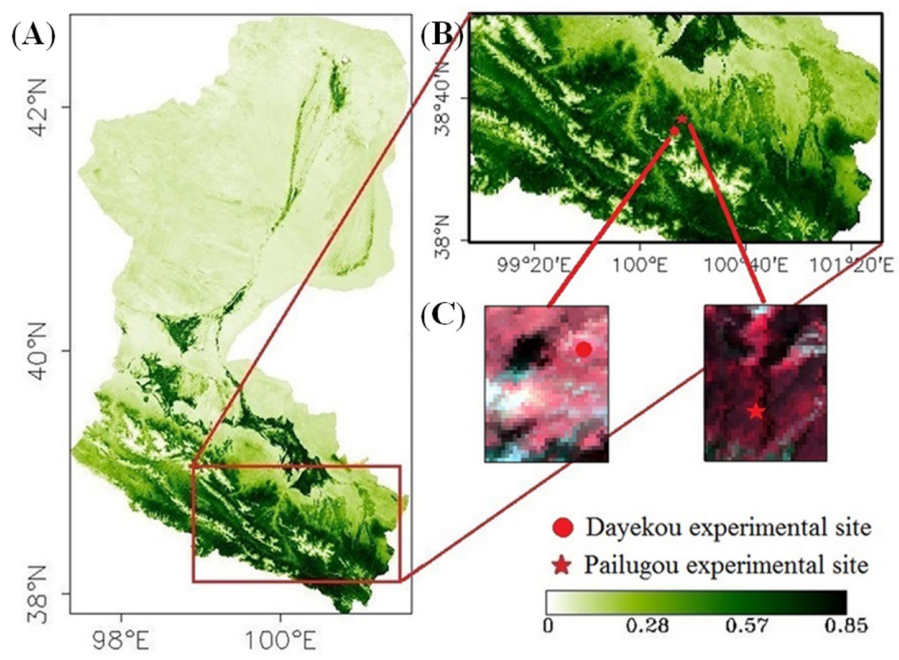


The interception loss was measured at two forest experimental sites, shown in Figure 2, from 13 June to 7 October in 2008. One site is named Dayekou forest hydrology experimental site with one experimental plot, and the other experimental site is named Pailugou forest hydrology experimental site with three experimental plots. The two sites had significantly different structures, representing the interception loss of different forest, though they are not very far from each other, and the two experiments were carried out separately. The main features of the experimental plots are shown in Table 1.

Table 1. Main features of the Dayekou and Pailugou experimental sites in the upper reaches of the Heihe River Basin in 2008.

\begin{tabular}{ccc}
\hline Features & Dayekou & Pailugou \\
\hline Location & $\left(100.258^{\circ} \mathrm{E}, 38.507^{\circ} \mathrm{N}\right)$ & $\left(100.295^{\circ} \mathrm{E}, 38.543^{\circ} \mathrm{N}\right)$ \\
Elevation $(\mathrm{m})$ & 3128 & 3250 \\
Tree species & picea crassifolia & picea crassifolia \\
Tree average height $(\mathrm{m})$ & 11.5 & 8.4 \\
Density (number of trees ha-1) & 1232 & 1880 \\
Average DBH (diameter at breast height) $(\mathrm{cm})$ & 16.3 & 13.2 \\
canopy cover $^{*}$ & 0.565 & 0.75 \\
Canopy storage $^{*}$ & 0.55 & 1.51 \\
Understorey & With some Bryophyta & With some Bryophyta \\
Plot dimensions $(\mathrm{m})$ & & $20 \times 15$ \\
& $25 \times 25$ & $10 \times 15$ \\
\end{tabular}

Note: *: determined using regression method.

\subsection{Remote Sensing Data}

The VAI and FVC can be retrieved from remote sensing observations. In this paper, we used two MODIS products: MOD15A2 LAI products and MOD13A2 NDVI products in 2008, provided by the MODIS land team of the National Aeronautics and Space Administration (NASA) Earth Observing System (EOS) project. Spatial resolution of all the MODIS data is $0.01^{\circ}$ and temporal resolution is eight days.

Land cover data is provided by the Heihe experimental data center that combined the land use data covering many years with the MOD12Q1 product using the International Geosphere Biosphere Programme (IGBP) classification [30].

The fraction of forest (FF) in pixel where the experimental sites were located was estimated from the classification of the Hyperion image, with a resolution of $30 \mathrm{~m}$, on 15 June 2008. The modelled interception loss is based on per unit area of ground, but the measurements are based on per unit area of forest, so FF can be used to convert the former to the latter when validating modelled interception loss.

There are two types of rainfall data used in this study. One is the field measured rainfall data, which was used to validate the RS-Gash model. Another is the product of Tropical Rainfall Measuring Mission (TRMM) TRMM 3B42, with temporal resolution of $3 \mathrm{~h}$ and spatial resolution of $0.25^{\circ}$. The linear interpolation method was used to obtain a finer spatial resolution at $0.01^{\circ}$, which was then used to map the interception loss of the study area. TRMM is a joint mission between NASA and the Japan 
Aerospace Exploration Agency (JAXA) designed to monitor and study tropical rainfall (more information see [31]).

\subsection{Meteorological Forcing Data}

In the Dayekou forest hydrology experimental site, one Automatic Weather Station (AWS) was built which can measure net radiation, wind speed, air temperature, air pressure and air humidity. The detailed information of the measured variables used in this study is listed in Table 2.

Table 2. The detailed information of the measured variables used in this study from the Automatic Weather Station (AWS) at the Dayakou forest hydrology experimental site.

\begin{tabular}{|c|c|c|c|c|}
\hline Variables & Sensor & Manufacturer & $\begin{array}{c}\text { Observation } \\
\text { accuracy }\end{array}$ & $\begin{array}{c}\text { Observed } \\
\text { altitude }\end{array}$ \\
\hline Tair $24 \mathrm{~m}$ & HMP45C & $\begin{array}{c}\text { Vaisala } \\
\text { (Helsinki, Finland) }\end{array}$ & $\pm 0.2{ }^{\circ} \mathrm{C}$ & $23.75 \mathrm{~m}$ \\
\hline Humidity $24 \mathrm{~m}$ & HMP45C & $\begin{array}{c}\text { Vaisala } \\
\text { (Helsinki, Finland) }\end{array}$ & $\pm 2 \%$ & $23.75 \mathrm{~m}$ \\
\hline Wind speed $24 \mathrm{~m}$ & 034B & $\begin{array}{c}\text { MetOne } \\
\text { (Grants Pass, OR, } \\
\text { USA) }\end{array}$ & $\pm 0.11 \mathrm{~m} / \mathrm{s}$ & $24.00 \mathrm{~m}$ \\
\hline Pressure & CS105 & $\begin{array}{c}\text { Campbell } \\
\text { (Logan, UT, USA) }\end{array}$ & $\pm 0.5 \mathrm{mb}$ & $0.50 \mathrm{~m}$ \\
\hline Short-wave radiation (upward and downward) & CM3 & $\begin{array}{c}\text { Campbell } \\
\text { (Logan, UT, USA) }\end{array}$ & $\pm 10 \%$ & $19.75 \mathrm{~m}$ \\
\hline Long-wave Radiation(upward and downward) & CG3 & $\begin{array}{c}\text { Campbell } \\
\text { (Logan, UT, USA) }\end{array}$ & $\pm 10 \%$ & $19.75 \mathrm{~m}$ \\
\hline
\end{tabular}

\subsection{Validation Data}

\subsubsection{Dayekou Experimental Site}

Gross rainfall was measured using two manual collecting rain-gauges with a $20 \mathrm{~cm}$ diameter set up on the open ground beside the tree canopy.

Throughfall was measured with 10 troughs with dimensions $100 \mathrm{~cm}$ long, $20 \mathrm{~cm}$ wide and $25 \mathrm{~cm}$ high. Nine of them were placed in a $3 \times 3$ grid, $12.5 \mathrm{~m}$ apart from each other. The remaining one was placed on the ground in between the $3 \times 3$ array. The rain-gauges and troughs were cleaned up after the rainfall (sometimes on the next day for night rainfall). For single rainfall, measurements of throughfall larger than gross rainfall were discarded. The average throughfall was calculated by the method of Herbst et al. [32], which adjusted the remainder according to their relative contribution to the average when all troughs were working. It should be noted that this method has a disadvantage: there are some errors when the missing data are the smallest or largest so that the throughfall might be underestimated if the amount of abandoned data is larger. Consequently, the measured interception loss will be slightly overestimated. 
Stemflow was collected from five trees using coiled pipes randomly. The stand-scale stemflow volume (in $\mathrm{mm}$ ) was calculated by taking into account the tree density of the plot.

There were a total of 25 rainfall data in the Dayekou site from 13 June to 7 October 2008, assuming that there was only one storm per rainday as Gash did [6]. The total gross rainfall was $162.8 \mathrm{~mm}$ with a total rainfall time of $220.6 \mathrm{~h}$.

\subsubsection{Pailugou Experimental Site}

Gross rainfall was measured using three siphon rainfall recorders set up on the open ground beside the tree canopy. Throughfall in each plot was measured with six troughs with dimensions $100 \mathrm{~cm}$ long, $20 \mathrm{~cm}$ wide and $25 \mathrm{~cm}$ high. All of them were placed in a fixed grid. For single rainfall, outliers were removed using the same method as for the Dayekou site. Since three siphon rainfall recorders were used at the Pailugou site, additional data screening policy is applied: for one rainfall event, if the difference of gross rainfall measurements between any two recorders among the three is larger than $1 \mathrm{~mm}$, the measurements are considered ineffective and screened out.

Stemflow was collected from nine trees using coiled pipes randomly. The stand-scale stemflow volume (in $\mathrm{mm}$ ) was calculated by taking into account the average tree density of the three plots.

There were a total of 23 rainfall data in the period from 13 June to 7 October 2008, assuming that there was only one storm per rainday as Gash did [6]. The total gross rainfall amount was $153.5 \mathrm{~mm}$ and the total rainfall time of $147 \mathrm{~h}$.

\section{Results and Analysis}

\subsection{Parameters for the RS-Gash Model}

Firstly, the RS-Gash model was verified using the filed measured rainfall and the parameters based on satellite as described below. After that, an interception loss map was created using the rainfall data from TRMM and the same parameters. Fraction of forest (FF) of the two experimental sites $\left(0.01^{\circ} \times 0.01^{\circ}\right.$, Dayekou and Pailougou experimental sites $)$, was calculated from the Hyperion image used in the field validation.

The VAI and FVC was derived from MODIS LAI and NDVI products after processing using HANTS (Harmonic Analysis of Time Series) [33] to get a gap-free time series with temporal resolution of eight days. Equations (9) and (10) were used to calculate the VAI with $L_{s, \min }=1$ and $\alpha=0.85$ for 8-day MODIS LAI products of picea crassifolia forest. Equation (14) was used to calculate the FVC with $N D V I_{f v}=0.8$ and $N D V I_{b s}=0.125$. Considering the seasonal variation of VAI and FVC due to seasonally dependent photosynthetic activity with the model running at daily steps, daily VAI and FVC time series were obtained by linear interpolation of the 8-day time series, based on the assumption that daily VAI and FVC would change linearly between the two products.

For specific vegetation storage $S_{V}$, we used the value $\left(S_{V}=0.35\right)$ of picea crassifolia, which is the same species as our forest study just a different location measured by Lankreijer et al. [26] with the regression method, since this parameter was not measured during our experiment. The value is maybe a little different from our study, due to differences in canopy structures such as stem density, canopy height, and leaf area index between the two study areas. However, a small difference in $S_{V}$ has limited 
influence on our study, according to the sensitivity analysis (see Section 5.4) which shows that $\pm 20 \%$ error of $S_{V}$ only results in less than $0.2 \mathrm{~mm}( \pm 0.16 \mathrm{~mm})$ error. The mean evaporation rate $\overline{E_{V}}$ was calculated by Equation (11) using meteorological data of AWS (listed in Table 2) for the periods when rainfall was larger than $0.5 \mathrm{~mm} \cdot \mathrm{h}^{-1}$ [6]. Since the study area $\left(1^{\circ} \times 2.5^{\circ}\right)$ is relative small, the difference in meteorological conditions over this study area can also be considered as relatively small. Consequently, it is acceptable to take a unique value of $\overline{E_{V}}$ over the study area. In our study, $\overline{E_{V}}=0.2 \mathrm{~mm} \cdot \mathrm{h}^{-1}$.

In the filed validation, we used the measured rainfall at the station, and the mean rainfall rate $\bar{R}$ is calculated from these data when the rainfall was larger than $0.5 \mathrm{~mm} \cdot \mathrm{h}^{-1}$. After the validation, an interception loss map using TRMM data was created at regional scale, and $\bar{R}$ was calculated using TRMM 3B42 data during the period when the rainfall was larger than $0.5 \mathrm{~mm} \cdot \mathrm{h}^{-1}$.

To compare the estimated interception loss with the ground measurements, the modelled interception loss was extracted from the two pixels where the two experimental sites were located. The fraction of forest (FF) in each one of the site-pixels $\left(0.01^{\circ} \times 0.01^{\circ}\right)$ is calculated by the maximum likelihood method from the fine resolution Hyperion image $(30 \mathrm{~m} \times 30 \mathrm{~m})$. The FF in the Dayekou and Pailugou experimental sites was 0.8 and 0.61 , respectively.

\subsection{Field Validation}

To directly verify the RS-Gash model, and avoid the bias due to the difference between TRMM rainfall data and field measured rainfall, the field measured rainfall data together with the other parameters based on satellite data were used in the field validation. In this study the RS-Gash model was evaluated first on a daily scale (single rainfall), and further for the whole period of observations, from 13 June to 7 October 2008.

The interception loss modelled ( $I_{\text {modelled }}$ ) by the RS-Gash model using remote sensing observations is presented in mm per unit area of ground, but the measurements are presented in mm per unit area of forest [22]. So for the validation study, the FF was used to convert the interception loss from per unit area of ground to per unit area of forest, as:

$$
I_{\text {correct }}=I_{\text {modelled }} / F F
$$

where, $I_{\text {correct }}$ is the interception loss after correction by $F F$, which can be used to compare with the measured interception loss directly.

The modelled interception loss for single rainfall is in good agreement with the field measurements at the Dayekou experimental site with a $R^{2}$ of 0.91 and RMSE of $0.34 \mathrm{~mm} \cdot \mathrm{h}^{-1}$ (Figure 3a), at Pailugou experimental site with a $R^{2}$ of 0.82 and RMSE of $0.6 \mathrm{~mm} \cdot \mathrm{h}^{-1}$ (Figure 3b). Figure 4 presents the correlation between the modelled interception loss and the ground observed gross rainfall at the two sites. The interception loss, both modelled and measured, increases with gross rainfall. This shows that the gross rainfall is an important factor for the interception loss. For small/light rainfall, the interception loss is a little underestimated, and the main reason might be that the wind in the forest may change the pathway of raindrops during falling thus increasing the interception loss. However, the model does not consider this. Yet, the wind has little effect on a large rainfall. In all, the high $R^{2}$ and the low RMSE demonstrate the competence of the modified model at regional scale. 
Figure 3. Validation of the modelled interception loss of a single rainfall using the RS-Gash model against field measurements for the period from 13 June to 7 October 2008. (A) The Dayekou experimental site; (B) The Pailugou experimental site.
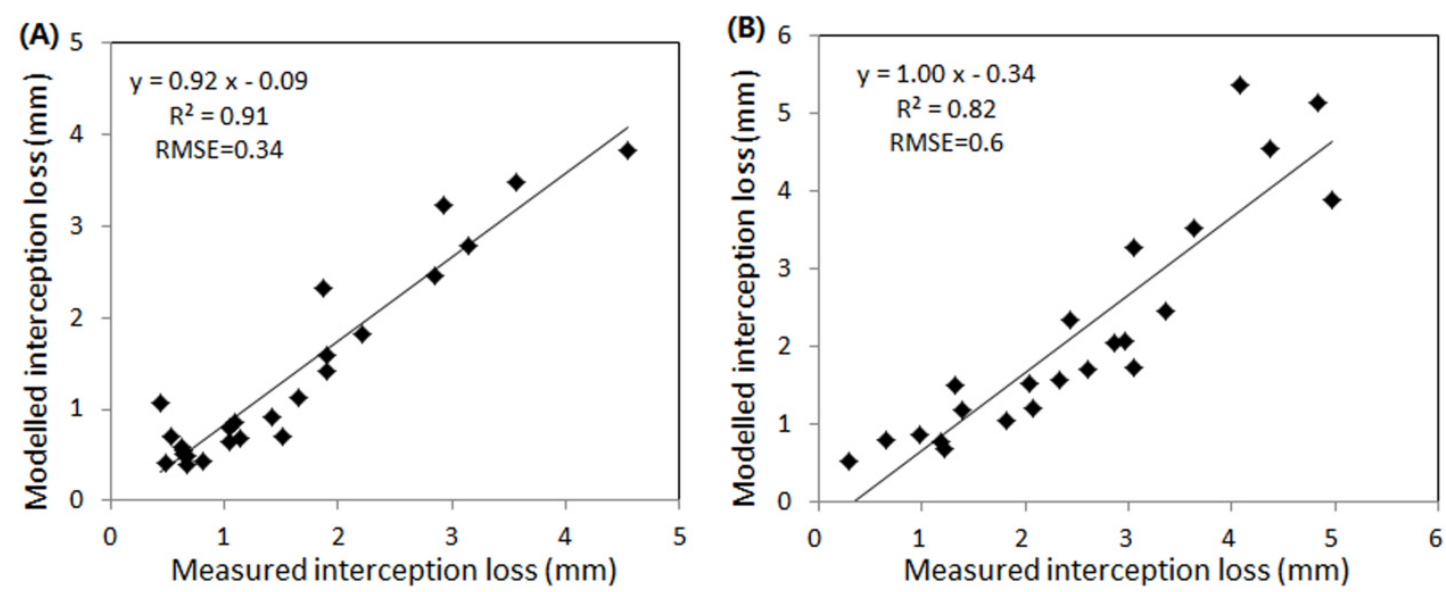

Figure 4. Correlation between the interception loss and the ground observed gross rainfall at the two sites for the period from 13 June to 7 October 2008. (A) The Dayekou experimental site; (B) The Pailugou experimental site.

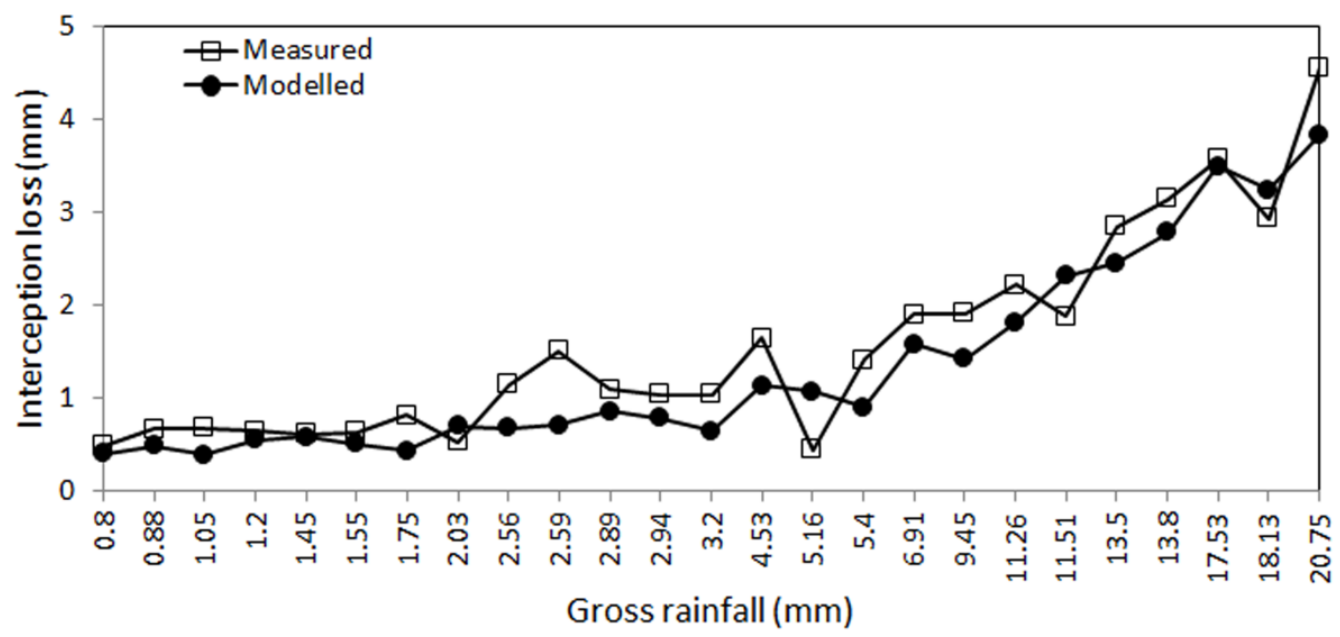

(A)

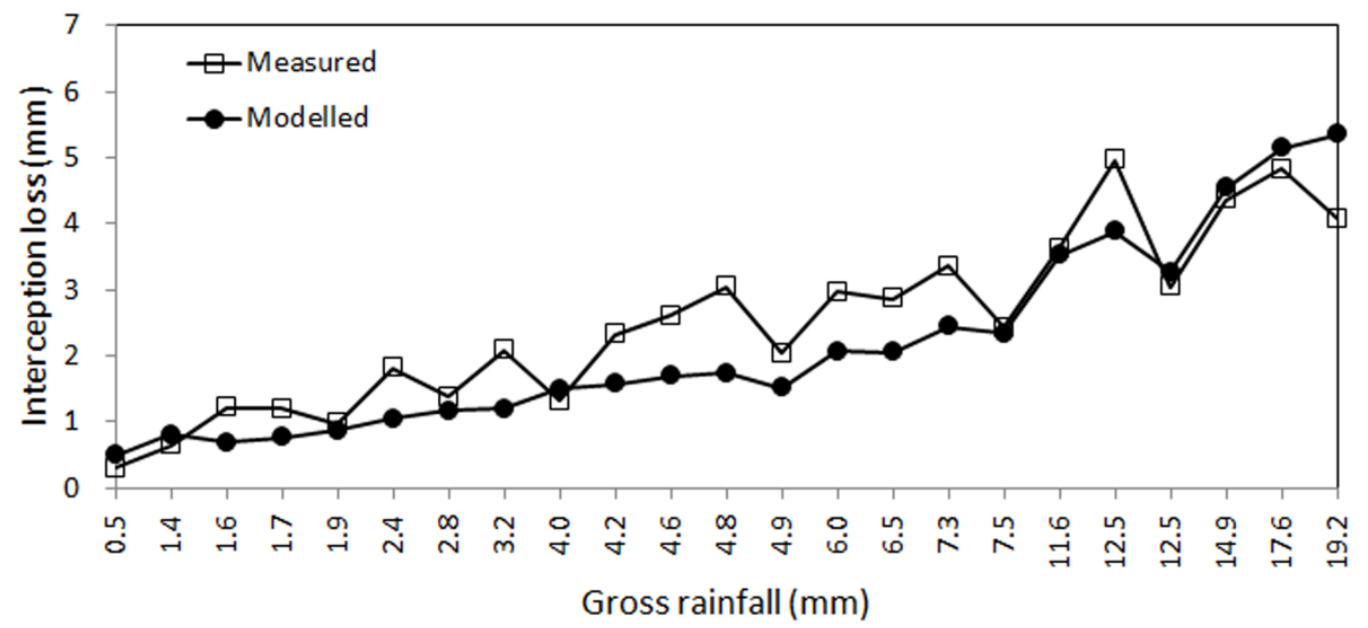

(B) 
The modelled and measured total interception loss are listed in Table 3 for the period from 13 June to 7 October 2008. From the comparison done at the two experimental sites, modelled interception loss was underestimated by about $14.2 \%$ and $13.6 \%$ of the measured interception loss, respectively. Considering the uncertainty of the parameters from the satellite due to the different scale, especially the FVC, VAI and FF, the error is acceptable. Although the RS-Gash model can reasonably estimate the interception loss of the most of single rainfall events, there are still some extreme cases with a high relative error. One of the reasons is that $\overline{E_{V}} / \bar{R}$ is the average of a period, in the case of deviation from the average conditions (some extreme cases in energy and wind speed) large errors in the input might be propagated to the estimated interception loss. Nevertheless, the model is steady enough for a reasonable estimation with acceptable error for the data used in this study as shown in Section 5.4. On the other hand, the measured errors should not be overlooked. The measured interception loss is very sensitive to the gross rainfall and throughfall. Because interception loss is measured as the relatively small difference between gross and net rainfall (throughfall and steamflow), even small errors in these measurements can result in high relative errors in interception loss and any error of these could be included in the interception loss [12], the validation data processing can only partly eliminate the error.

Table 3. The modelled and measured total interception loss at the two sites.

\begin{tabular}{|c|c|c|c|c|c|c|}
\hline \multirow{2}{*}{ Site } & \multirow{2}{*}{$\begin{array}{c}\text { Gross rainfall }\left(P_{\mathrm{g}}\right) \\
(\mathrm{mm})\end{array}$} & \multicolumn{2}{|c|}{ Modelled } & \multicolumn{2}{|c|}{ Measured } & \multirow{2}{*}{$\begin{array}{l}\text { Relative error } \\
\text { (\% measured) }\end{array}$} \\
\hline & & $\mathbf{m m}$ & $\% P_{g}$ & $\mathbf{m m}$ & $\% P_{g}$ & \\
\hline Dayekou & 162.8 & 33.8 & 20.8 & 39.4 & 24.2 & 14.2 \\
\hline Pailugou & 153.5 & 49.7 & 32.4 & 57.5 & 37.5 & 13.6 \\
\hline
\end{tabular}

The variation of the interception loss at a regional scale results from the heterogeneity of parameters, such as: VAI, FVC and the mean rainfall rate $\bar{R}$. There are two points needed to be stated when using remote sensing to estimate the interception loss at a regional scale. Firstly, there are several unavoidable random errors in results, especially for the mixed pixels. However, with significant classification, the estimated interception loss can also represent the interception loss of the vegetation type. Secondly, the results of modelled interception loss are based on per unit area of ground, but the measurements are based on per unit area of forest. The former has a direct significance for regional water cycle researches and can meet the demand of most of the researches, so there is no need to convert the former to the latter, except for validation.

\subsection{Interception Loss of Forest at Regional Scale}

Considering the picea crassifolia forest is the main coniferous forest in the study area and information on finer forest classification is not available for the time being, we took the class of coniferous forest in the land cover map to estimate the regional forest interception loss in the study area. The estimated regional distribution of forest rainfall interception loss from 13 June to 7 October 2008 using the RS-Gash model is presented in Figure 5c,d together with the regional distribution of FVC and VAI (Figure 5a,b). Both the absolute values of interception loss (Figure 5c) and the interception loss as a percentage of the gross rainfall (Figure 5d) showed great spatial variation. The statistical results of FVC, VAI and interception loss are shown in Table 4. 
Table 4. The variation of Fractional Vegetation Cover (FVC), Vegetation Area Index (VAI) and interception loss (in mm and \%) in the spatial from 13 June to 7 October 2008.

\begin{tabular}{ccc}
\hline Variables & Mean & Standard deviation \\
\hline FVC & 0.47 & 0.16 \\
VAI & 1.94 & 0.64 \\
Interception loss (mm) & 61.1 & 26.1 \\
Interception loss (\%) & 20.05 & 6.4 \\
\hline
\end{tabular}

The spatial variation of interception loss is clearly attributed to the varying density of the forest as expressed by FVC and VAI in space in addition to rainfall spatial variation. Larger errors might be expected in mixing pixels, in particular at the edge of a large forest area, due to the fact that non-forest pixels might be mis-classed as forest leading to underestimation of the modeled interception loss, and vice versa.

Figure 5. The spatial distribution of (A) the Fractional Vegetation Cover (FVC); (B) the Vegetation Area Index (VAI); (C) the interception loss (mm); and (D) the interception loss in percentage of gross rainfall (\%). Values in the maps are the average over the period from 13 June to 7 October 2008.
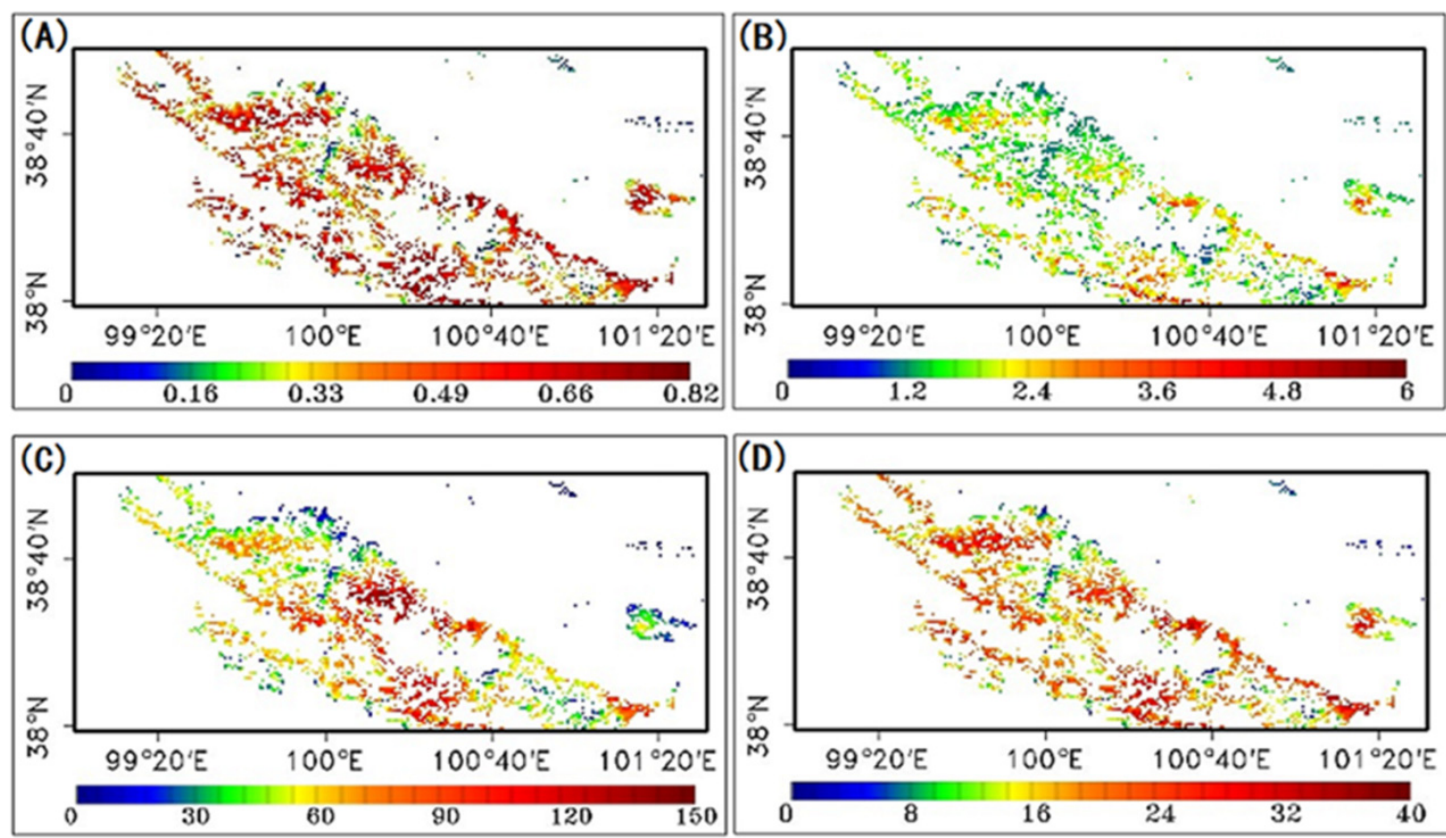

\subsection{Sensitivity Analysis of the Model}

There are five parameters used in the RS-Gash model including VAI, FVC, specific vegetation storage $S_{V}$ (used to calculate the vegetation storage capacity $S_{v e g}$ ), mean evaporation rate $\overline{E_{V}}$, and mean rainfall rate $\bar{R}$. The values of these parameters can be determined by remote sensing observations directly or indirectly, by field measurements, or by taking as empirical values when applying the model at regional scale. Errors of these parameters are unavoidable and may have different effects on the estimated interception loss at different gross rainfall levels. It is necessary to evaluate the 
sensitivity of the model to these parameters. One dataset used in our study on Picea crassifolia forest were taken as the baseline for the sensitivity study. The sensitivity analysis is done by adding $\pm 20 \%$ and $\pm 10 \%$ of errors to each one of the parameters while keeping the others constant. The difference between the Poisson distribution and the uniform distribution was also analyzed.

The baseline values of the parameters are as follows: $V A I=2.5 ; F V C=0.6 ; S_{V}=0.35 ; \overline{E_{V}}=0.2 \mathrm{~mm} \cdot \mathrm{h}^{-1}$; $\bar{R}=1.0 \mathrm{~mm} \cdot h^{-1}$. The sensitivity of the estimated interception loss on each parameter is shown in Figure 6 . The result of interception loss vs. gross rainfall between the Poisson distribution and the uniform distribution is shown in Figure 7.

Figure 6. Sensitivity of the estimated interception loss on: (A) $S_{V} ;(\mathbf{B}) \mathrm{VAI} ;(\mathbf{C}) \mathrm{FVC} ;(\mathbf{D}) \bar{R} ;(\mathbf{E}) \overline{E_{V}}$.

There are several findings from the results of the sensitivity simulations:

1、For VAI and $S_{V}$, the error of interception loss was a constant and equal to $\Delta_{V A I} S_{V}$ or $\Delta s_{v} \cdot V A I$ when $P_{G}>P_{G}^{\prime}$;

2、 For FVC $、 \overline{E_{V}} 、 \bar{R}$, the error of interception loss is linear with gross rainfall, and the coefficient is $\Delta_{F V C}, \Delta_{\overline{E_{V}}}$ and $\Delta_{1 / \bar{R}}$, when $P_{G}>P_{G}^{\prime}$, respectively;

3、 Interception loss using the Poisson distribution is smaller than using uniform distribution, and there are maximum errors near to $S_{V} V A I / F V C$. However the error can be neglected for relatively larger or smaller rainfall. For forest, $S_{V} V A I / F V C$ can range from $1 \mathrm{~mm}$ to $10 \mathrm{~mm}$, so the heterogeneity of the pixel cannot be neglected, especially for the arid region where the rainfall is dominated by small rainfall.

In general, estimated interception loss is robust and not overtly sensitive to any of the inputs. The sensitivity analysis has shown that changes in any of the input terms $(x)$ in the model yield a conservative change $(d I / d x<1)$ in predicted $I$ (Figure 7).

Figure 7. The results of interception loss vs. gross rainfall between Poisson distribution and uniform distribution, where $S_{V} V A I / F V C$ is equal to $3(\mathrm{~mm}), 6(\mathrm{~mm})$ and $10(\mathrm{~mm})$ respectively.

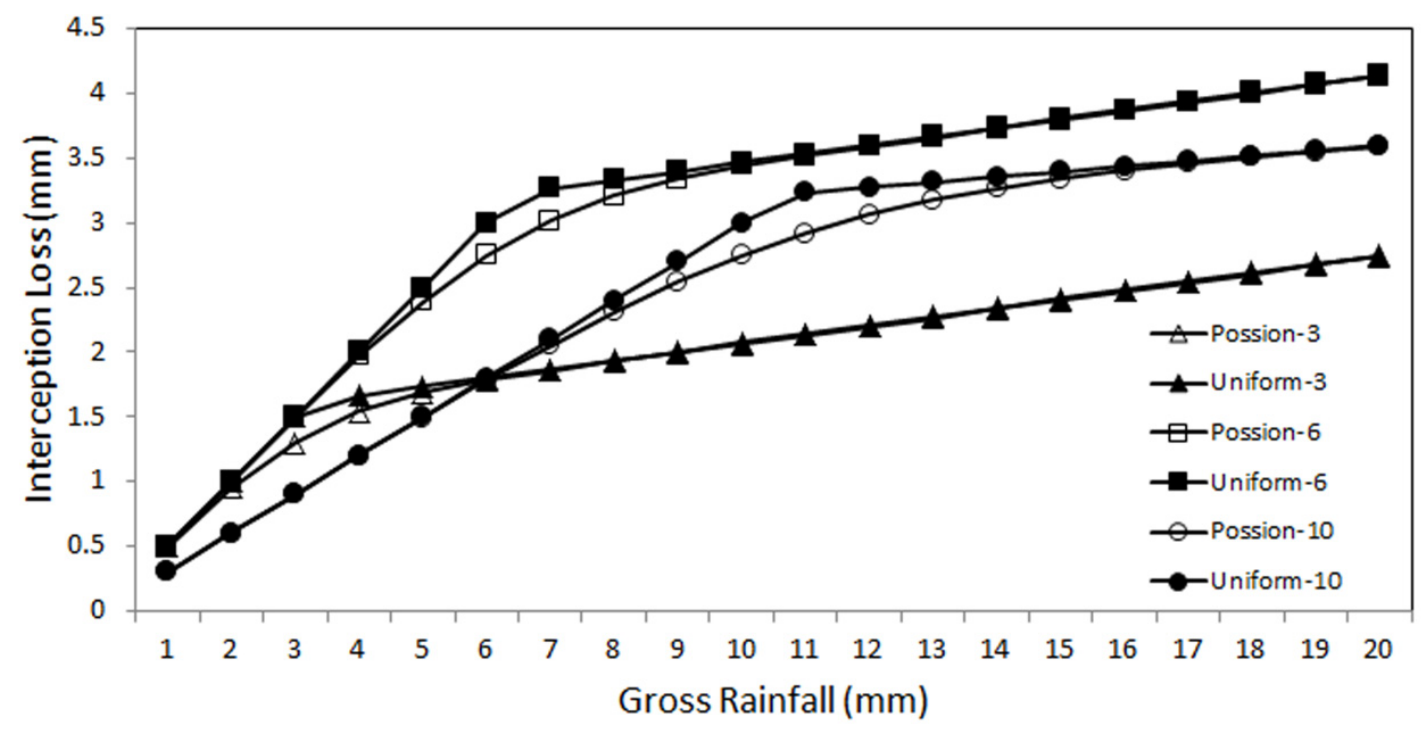

\section{Conclusions}

A RS-Gash model was developed based on the Gash (1995) model to estimate the interception loss of heterogeneous forest using remote sensing observations of forest canopy structure parameters and gross rainfall. Compared with the original Gash (1995) model, the improvements in the RS-Gash model are: (1) The forest canopy and trunk are taken as one unity without distinguishing them as in the original Gash (1995) model. In turn, "canopy" related parameters are replaced by "vegetation" related parameters, e.g., "canopy storage capacity" is replaced by "vegetation storage capacity"; (2) Utilizing a simple linear relationship to represent the vegetation storage capacity, the latter can be easily obtained from remote sensing observations; (3) Using FVC to replace $c$ allows the evaporation from saturated 
trunk to be included in the model; (4) Contrary to the assumption of uniform forest, the heterogeneity of vegetation distribution both at pixel and at sub-pixel scales is considered in the RS-Gash model.

For validation, of a single rainfall, the modelled interception loss is in good agreement with the field measurements at the Dayekou $\left(R^{2}=0.91\right.$ and $\left.R M S E=0.34 \mathrm{~mm} \cdot \mathrm{d}^{-1}\right)$ and Pailugou $\left(R^{2}=0.82\right.$ and $\left.R M S E=0.6 \mathrm{~mm} \cdot \mathrm{d}^{-1}\right)$ experimental sites, showing that the model can be used on a daily scale, assuming that there is only one storm per rainday. For the measured period, the modelled interception losses were underestimated by about $14.2 \%$ and $13.6 \%$ measured at Dayekou and Pailugou experimental sites, respectively, because of the uncertainty of the parameters coming from the satellite at a different scale. For the study area which is in an inland river basin, there are many small rainfall events, so the effect of vegetation heterogeneity should not be neglected.

In this study, we assumed that the $\overline{E_{V}}$ is a constant. This is reasonable for this study due to the relative small area of the study area. Whereas, when the RS-Gash model is applied on a much larger scale, such as the basin scale, the spatial variation of $\overline{E_{V}}$ should be considered. Until now, there are several regional near-surface meteorological forcing data products produced, based on model simulation, and this issue may be solved but there remains other challenging work.

\section{Acknowledgements}

This work was jointly supported by the "China Academy of Sciences, State Bureau of foreign experts and international innovation Partnership Program" project (Grant No. KZZD-EW-TZ-09), the National High Technology Research and Development Program of China (Grant No. 2012AA12A304). The authors thank the anonymous reviewers for their valuable comments. The authors would like to sincerely thank the WATER program for providing the in situ measurements.

\section{Author Contributions}

Yaokui Cui wrote the paper; Li Jia supervised the study, reviewed and edited the manuscript. All authors read and approved the manuscript.

\section{Conflicts of Interest}

The authors declare no conflict of interest.

\section{References}

1. Scatena, F.N. Watershed scale rainfall interception on 2 forested watersheds in the luquillo mountains of puerto-rico. J. Hydrol. 1990, 113, 89-102.

2. Asdak, C.; Jarvis, P.G.; van Gardingen, P.; Fraser, A. Rainfall interception loss in unlogged and logged forest areas of central kalimantan, Indonesia. J. Hydrol. 1998, 206, 237-244.

3. Levia, D.F.; Frost, E.E. Variability of throughfall volume and solute inputs in wooded ecosystems. Prog. Phys. Geog. 2006, 30, 605-632.

4. Calder, I.R. Water use by forests, limits and controls. Tree Physiol. 1998, 18, 625-631.

5. Jackson, I.J. Relationships between rainfall parameters and interception by tropical forest. $J$. Hydrol. 1975, 24, 215-238. 
6. Gash, J.H. An analytical model of rainfall interception by forests. Q. J. Roy. Meteor. Soc. 1979, $105,43-55$.

7. Rutter, A.J.; Robins, P.C.; Morton, A.J.; Kershaw, K.A. Predictive model of rainfall interception in forests.1. Derivation of model from observations in a plantation of corsican pine. Agr. Meteorol. 1972, 9, 367-384.

8. Gash, J.H.C.; Lloyd, C.R.; Lachaud, G. Estimating sparse forest rainfall interception with an analytical model. J. Hydrol. 1995, 170, 79-86.

9. Liu, S.G. Estimation of rainfall storage capacity in the canopies of cypress wetlands and slash pine uplands in North-Central Florida. J. Hydrol. 1998, 207, 32-41.

10. Van Dijk, A.I.J.M.; Bruijnzeel, L.A. Modelling rainfall interception by vegetation of variable density using an adapted analytical model. Part 1. Model description. J. Hydrol. 2001, 247, 230-238.

11. Murakami, S. A proposal for a new forest canopy interception mechanism: Splash droplet evaporation. J. Hydrol. 2006, 319, 72-82.

12. Muzylo, A.; Llorens, P.; Valente, F.; Keizer, J.J.; Domingo, F.; Gash, J.H.C. A review of rainfall interception modelling. J. Hydrol. 2009, 370, 191-206.

13. Bastiaanssen, W.G.M.; Cheema, M.J.M.; Immerzeel, W.W.; Miltenburg, I.J.; Pelgrum, H. Surface energy balance and actual evapotranspiration of the transboundary indus basin estimated from satellite measurements and the etlook model. Water Resour. Res. 2012, 48, W11512.

14. Von Hoyningen, H.J. Die interception des niederschlags in landwirtschaftlichen bestanden. Schriftenr. DVWK 1983, 57, 1.

15. $\mathrm{Mu}$, Q.Z.; Zhao, M.S.; Running, S.W. Improvements to a modis global terrestrial evapotranspiration algorithm. Remote Sens. Environ. 2011, 115, 1781-1800.

16. Hutjes, R.W.A.; Wierda, A.; Veen, A.W.L. Rainfall interception in the tai forest, ivory-coast-Application of 2 simulation-models to a humid tropical system. J. Hydrol. 1990, 114, 259-275.

17. Valente, F.; David, J.S.; Gash, J.H.C. Modelling interception loss for two sparse eucalypt and pine forests in central portugal using reformulated rutter and gash analytical models. J. Hydrol. 1997, $190,141-162$.

18. Schellekens, J.; Scatena, F.N.; Bruijnzeel, L.A.; Wickel, A.J. Modelling rainfall interception by a lowland tropical rain forest in northeastern puerto rico. J. Hydrol. 1999, 225, 168-184.

19. Motahari, M.; Attarod, P.; Pypker, T.G.; Etemad, V.; Shirvany, A. Rainfall interception in a pinus eldarica plantation in a semi-arid climate zone: An application of the gash model. J. Agr. Sci. Tech. Iran. 2013, 15, 981-994.

20. Van Dijk, A.I.J.M.; Bruijnzeel, L.A. Modelling rainfall interception by vegetation of variable density using an adapted analytical model. Part 2. Model validation for a tropical upland mixed cropping system. J. Hydrol. 2001, 247, 239-262.

21. Zeng, X.B.; Shaikh, M.; Dai, Y.J.; Dickinson, R.E.; Myneni, R. Coupling of the common land model to the ncar community climate model. J. Clim. 2002, 15, 1832-1854.

22. Miralles, D.G.; Gash, J.H.; Holmes, T.R.H.; de Jeu, R.A.M.; Dolman, A.J. Global canopy interception from satellite observations. J. Geophys. Res. Atmos. 2010, 115, doi: 10.1029/2009JD013530.

23. Pitman, J.I. Rainfall interception by bracken in open habitats-Relations between leaf-area, 
canopy storage and drainage rate. $J$. Hydrol. 1989, 105, 317-334.

24. Llorens, P.; Gallart, F. A simplified method for forest water storage capacity measurement. $J$. Hydrol. 2000, 240, 131-144.

25. Aston, A.R. Rainfall interception by 8 small trees. J. Hydrol. 1979, 42, 383-396.

26. Lankreijer, H.; Lundberg, A.; Grelle, A.; Lindroth, A.; Seibert, J. Evaporation and storage of intercepted rain analysed by comparing two models applied to a boreal forest. Agr. Forest Meteorol. 1999, 98-99, 595-604.

27. Monteith, J.L. Evaporation and environment. Symp. Soc. Exp. Biol. 1965, 19, 205-223.

28. Myneni, R.B.; Ross, J.; Asrar, G. A review on the theory of photon transport in leaf canopies. Agr. Forest Meteorol. 1989, 45, 1-153.

29. Li, X.; Li, X.W.; Li, Z.Y.; Ma, M.G.; Wang, J.; Xiao, Q.; Liu, Q.; Che, T.; Chen, E.X.; Yan, G.J.; et al. Watershed allied telemetry experimental research. J. Geophys. Res. Atmos. 2009, 114, doi: 10.1029/2008JD011590.

30. Ran, Y.H.; Li, X.; Lu, L.; Li, Z.Y. Large-scale land cover mapping with the integration of multi-source information based on the dempster-shafer theory. Int. J. Geogr. Inf. Sci. 2012, 26, 169-191.

31. Tropical Rainfall Measuring Mission (TRMM). Available online: http://rmm.gsfc.nasa.gov/ (accessed on 16 April 2014).

32. Herbst, M.; Rosier, P.T.W.; McNeil, D.D.; Harding, R.J.; Gowing, D.J. Seasonal variability of interception evaporation from the canopy of a mixed deciduous forest. Agr. Forest Meteorol. 2008, 148, 1655-1667.

33. Jia, L.; Shang, H.; Hu, G.; Menenti, M. Phenological response of vegetation to upstream river flow in the heihe rive basin by time series analysis of modis data. Hydrol. Earth Syst. Sci. 2011, $15,1047-1064$.

(C) 2014 by the authors; licensee MDPI, Basel, Switzerland. This article is an open access article distributed under the terms and conditions of the Creative Commons Attribution license (http://creativecommons.org/licenses/by/3.0/). 